\title{
Bridging the Gap: Exploring the Impact of Hospital Isolation on Peer Relationships Among Children and Adolescents with a Malignant Brain Tumor
}

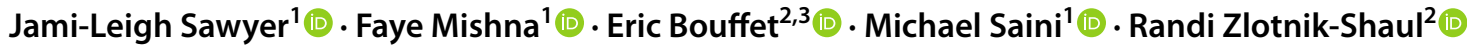

Accepted: 24 April 2021 / Published online: 18 May 2021

(c) The Author(s), under exclusive licence to Springer Science+Business Media, LLC, part of Springer Nature 2021

\begin{abstract}
Children and adolescents with complex medical conditions are often uprooted from their environments and isolated in hospital while undergoing treatment. Little is known about how they perceive this isolation and its subsequent impact on their relationships with peers, both during and after isolation for treatment. This study describes the experience of hospital isolation from the perspectives of children and adolescents with a malignant brain tumor. The use and impact of information and communication technologies (ICT) as a possible bridge for contact is also explored. Following a qualitative approach utilizing interpretive phenomenological analysis, in-depth interviews were conducted with eight youth participants who had undergone treatment for medulloblastoma. Data analysis generated three main themes: (1) transforming children and relationships, (2) hospitalization in a digital world, and (3) ICTs as a promising bridge back to school. Study findings provide insight into the experience of hospital isolation for children and adolescents, while highlighting the positive social as well as academic outcomes of frequent, open ended ICT use throughout hospital isolation. This is timely, given the context of the COVID-19 pandemic and its resulting isolation. Considerations for hospital social workers to promote relationships and connection, while facilitating a smooth transition as these children return to school are included.
\end{abstract}

Keywords Peer relationships $\cdot$ Child development $\cdot$ Healthcare $\cdot$ Isolation $\cdot$ Information and communication technologies

Developing relationships with peers is a central component of typical childhood (Rubin, Chen, Coplan, Buskirk, $\&$ Wojslawowicz, 2005). Not only are peer relationships an important source of socialization, support, and friendship (Laxmi \& Kadapatti, 2012); developing positive relationships with peers has been found to foster social-emotional well-being (Guralnick, Neville, Hammond, \& Connor, 2007; Shin, Cho, Shin, \& Soon Park, 2016), as well as academic achievement (Wentzel, Jablansky, \& Scalise, 2020). Throughout development, the significance of relationships with parents and peers gradually alternates (Laxmi \&

Jami-Leigh Sawyer

jami.sawyer@mail.utoronto.ca

1 Factor-Inwentash Faculty of Social Work, University of Toronto, 246 Bloor Street West, Toronto, ON M5S1V4, Canada

2 The Hospital for Sick Children, Toronto, ON, Canada

3 Department of Paediatrics, University of Toronto, Toronto, ON, Canada
Kadapatti, 2012). While the family serves as the first source of social learning for children, this naturally shifts as they begin to spend increasingly more time at school with peers. Rather than debate the centrality of parents versus peers in child development however, it is critical to better understand the "interplay of different types of relationships within children's social networks" (Hay, Payne, \& Chadwick, 2004, p. 84). Relationships with both parents and peers are important, as early experiences with primary caregivers set the foundation for future relationships (Shaver, Mikulincer, \& Feeney, 2009).

Although typical developmental trajectories in childhood normally involve gradual movement away from relationships with family and shift towards relationships with peers (Laxmi \& Kadapatti, 2012), not all children are afforded this opportunity. Children and adolescents with complex medical conditions are often uprooted from their environments and isolated in hospital while undergoing treatment. The aim of hospital isolation is to either protect an immune-compromised patient from others (protective isolation), or to protect others from a patient's infectious disease (contact isolation) 
(Vottero \& Rittenmeyer, 2012). While some research exists on the effects of hospital isolation, very little focuses on pediatric populations (Cohen, Austin, Weinstein, Matlow, $\&$ Redelmeier, 2008), and even fewer studies utilize qualitative methods to reveal the voices of children (Alvarez, Pike, \& Godwin, 2020; Austin, Prieto, \& Rushforth, 2013). Furthermore, much of the existing research is very dated (e.g. Hollenbeck et al., 1980; Powazek, Goff, Schyving, \& Paulson, 1978), and often combines children experiencing a wide range of medical diagnoses (e.g., Alvarez et al., 2020; Musiello, Platt, Plaster, Haddow, \& Ives, 2014), or relies on the parents' report of the child's experience (Tsironi, \& Koulierakis, 2017). While it is clear that hospital isolation increases risk of mental health problems including anxiety, depression, and anger (Abad, Fearday, \& Safdar, 2010), little is known about how children and adolescents perceive this isolation and its subsequent impact on their relationships with peers, both during and after isolation for treatment.

Being physically isolated from peers and school to undergo treatment undoubtedly affects development. A population impacted by this type of isolation are children and adolescents diagnosed with medulloblastoma, the most frequently occurring malignant brain tumor in childhood (Ramaswamy, Nor, \& Taylor, 2016). Treatment for this type of malignant brain tumor is intensive and requires children and adolescents to stay in a protective isolation room in the hospital to guard against infections (Berlin-Romalis \& Doyle, 2010). Consequently, the visiting policy is very strict, typically limiting visitors to immediate caregivers only. Depending on the hospital policy, children and adolescents are usually unable to see peers in person and are typically required to stay out of school from between 3 and 9 months, and oftentimes miss an entire academic year (Vannatta, Zeller, Noll, \& Koontz, 1998). Children and youth with a malignant brain tumour have already been identified as vulnerable to psychosocial impairments such as increased use of special education, lower rates of independent living as adults, and impaired vocational and social opportunities (Hoppe-Hirsch et al., 1990; Packer et al., 2003). To mediate possible negative effects psychosocially both immediately as well as in the long term, it is critical to better understand the isolation experiences of these children and youth.

Pediatric brain tumor survivors are considered especially vulnerable to social impairments following treatment (Barrera, Shaw, Speechley, Maunsell, \& Pogany, 2005; Krull, Hardy, Kahalley, Schuitema, \& Kesler, 2018; Stam, Grootenhuis, \& Last, 2001; Vannatta et al., 1998). Compared to children with other cancers, pediatric brain tumor survivors experience greater difficulty with social adjustment (Schulte \& Barrera, 2010), and are less likely to report having close friends (Desjardins et al., 2019). There are significant negative social consequences for children who are survivors of pediatric brain tumors, since social withdrawal is a predictor of increased anxiety and depression (Desjardins et al., 2019). As children and youth with malignant brain tumors are already at risk of social impairments following their treatment (Barrera et al., 2005; Krull et al., 2018; Stam et al., 2001; Vannatta et al., 1998), there is a need to better understand the impact of hospital isolation and its required separation from peers during this critical developmental period. Despite reported negative consequences of hospital isolation, little is known about this experience from the perspectives of children and adolescents. To address this gap, this study utilizes qualitative methodology to examine the impact of hospital isolation for children and youth with a malignant brain tumor. This information is critical to promote social and emotional development for these children as they transition from hospital isolation back to their typical environments and their peers. Findings from this study are unique, and they provide insight into implications for social work practice within hospital isolation settings.

\section{Child Development and Peer Relationships}

Critical for child development (Wentzel, 2017), peer relationships influence behaviour, adjustment and socio-emotional learning starting at an early age (Hetherington, Parke, \& Schmuckler, 2003; Laxmi \& Kadapatti, 2012; Shin et al., 2016). Peers tend to act as role models for children, allowing them to develop new knowledge and responses through observation (Hay et al. 2004; Hetherington et al., 2003). Peer relationships help facilitate the development of many skills, including language, motor skills, social understanding, emotion regulation, cognitive abilities, academic achievement, self-efficacy, and they also contribute to mental health (Hartup \& Laursen, 1991; Hay et al., 2004; Wentzel, 2017). The school-age period is marked by an anticipated shift away from parents towards peers (Laxmi \& Kadapatti, 2012; Murray, 2000), which progresses into adolescence as growing independence shifts the focus towards peers and activities outside of the family (Foulkes \& Blakemore, 2018). While relationships with parents and peers appropriately evolve during this developmental period, parents continue to play a significant role in supporting their child's development, including their self-esteem, emotional well-being, social skills, and academic achievement (Laxmi \& Kadapatti, 2012). Parent involvement remains critical during this life stage, as "parents promote individuality by providing a secure base from which to explore the social world, yet it is the experience with age-mates that prompts the development of autonomy" (Laursen \& Bukowski, 1997, p. 747).

This alternating focus between family and peers continues through adolescence, a period of time that Erikson (1959) classified as occurring between the ages of 12 and 20, and 
the World Health Organization as between 10 and 19 (WHO, 2014). Adolescents experience significant changes as they mature physically and psychologically (Laxmi \& Kadapatti, 2012). According to Laxmi and Kadapatti (2012, p. 1) "normal adolescent development involves a gradual movement from the importance of the relationships with family towards the interpersonal relationship with peers for socialization, self definition, friendship and support". Peers play a significant role in helping adolescents achieve developmental competencies (Nesi, Choukas-Bradley, \& Prinstein, 2018) such as developing a sense of self and identity (Meeus, Iedema, Maassen, \& Engels, 2005; Pfeifer and Berkman, 2018). Connections between adolescent self-esteem and interpersonal relationships have also been found, as adolescents with higher self-esteem are more likely to experience high quality relationships with family, peers, and teachers $(\mathrm{Bi}, \mathrm{Ma}$, Yuan, \& Zhang, 2016).

\section{Protective Isolation in Hospital}

Unprecedented times in healthcare due to a pandemic have provided insights into the impact on children and adolescents of separation from peers. While the social impact of school closures has been cited as significant (Rashid et al., 2015); very little attention has been paid to the actual experience of isolation from the perspectives of children and adolescents. Even in the face of past school closure and public health recommendations to isolate from peers during an infectious disease outbreak, many children continued to leave their home environments to socialize (Brooks, 2020). This behaviour by youth is in contrast to those children and adolescents with medical conditions that require hospital isolation, as they have no choice but to remain in protective isolation to maintain their health and guard against infections. Hospital visiting policies have changed significantly over the years, largely in response to seminal work conducted by Bowlby (1960), and Robertson (1958). Through observations of hospitalized children, Bowlby and Robertson (1952) noted the detrimental impacts of social isolation on development. Together they proposed a model of distress in which children separated from their caregiver would progress through a series of three stages: first children would protest, wherein they would angrily cry and scream. When their protesting appeared to stop, children would enter the stage of despair, in which they would seem quiet and withdrawn. Finally, children would reach a point of detachment, whereby the child would begin to engage with others but reject their caregiver upon their return. In their documentary "A Two Year Old Goes to Hospital”, Bowlby and Robertson (1952) documented these progressive stages highlighting the serious emotional upset and possible psychological disturbance children experience when hospitalized and separated from their caregiver. Since this early work, research in the field of child development has progressed, resulting in significant changes to hospital policies that include allowing parents to remain with hospitalized children (e.g. Gammon, 1999; Koller, Nicholas, Salter Goldie, Gearing, \& Selkirk, 2006).

Hospital isolation is a typical component of treatment for children and adolescents undergoing treatment due to a malignant brain tumor. Very little is known about the experience and impact of isolation among youth dealing with a range of medical issues (Alvarez et al., 2020; Austin et al., 2013), let alone for this population. While comparable research with adults has indicated that hospital isolation heightens risk for psychological distress such as anxiety and depression (Purssell, Gould, \& Cudleigh, 2020), it is argued that the psychosocial experiences of hospital isolation for adults cannot be compared to children (Alvarez et al., 2020). In 2013, a systematic review was conducted on the experience of single room isolation for hospitalized children (Austin et al., 2013). The researchers emphasized the lack of scientific studies on the experience of isolation from the perspectives of children, which necessitated that clinical practice be guided by "limited child-specific research, relevant adult literature and conventional wisdom" (p. 18). This review entailed examination of 16 articles published between the years 1970 and 2011, which focused on the effects of hospital isolation for children. Notably, only three of these studies sought the children's perceptions of the isolation experience, whereas the other studies relied on either parent report or observational research. Of those three studies, one was published in 1985, and although dated, highlighted six children's fear of the isolation experience, including fear of the personal protective equipment that staff wore (Broeder, 1985). An ethnographic approach was used in the second study, which entailed interviews with five children isolated due to severe acute respiratory syndrome (SARS) epidemic (Koller et al., 2006). Findings indicated that children felt distressed as a result of the isolation, namely sad and lonely. In the third study, questionnaires with open and closed ended questions were administered to 101 children isolated for treatment related to cystic fibrosis (Russo, Donnelly, \& Reid, 2006). Although their response rate was low, questionnaire findings indicated that children strongly disliked being separated from peers. The only other comparable study examined the experiences of adolescents and young adults with cancer who were treated in adult hospitals in Western Australia. While this study utilized qualitative methodology to capture the voices of participants directly, its focus on isolation was from an experience in an adult setting with much older participants, thus not capturing the unique experiences of children and adolescents (Musiello et al., 2014). A qualitative study was recently published focusing on children's perceptions of contact isolation while hospitalized (Alvarez et al., 2020). Although participants 
were hospitalized for a wide range of medical issues, and experienced a different type of isolation than the type in the current study, it draws attention to the significant gap in the literature with respect to including children's voices. Given the paucity of existing and current research that obtains the voices of children to explore the hospital isolation experience, a significant gap exists in the literature.

\section{Isolation and Information and Communication Technologies}

Existing research has documented the positive impact of social opportunities on well-being for hospitalized children and youth. To be considered a psychosocially supportive environment, hospitals must provide opportunities for pediatric patients to access social support from parents and caregivers, as well as other pediatric patients (McLaughlan, 2018). Curtis and Northcott (2017) conducted a qualitative study exploring the impact of single versus shared rooms on patient experiences and well-being. Findings indicated that shared rooms were associated with the children reporting greater socialization while in hospital, compared to expressing increased boredom and decreased socialization in single rooms. Notably, nurses that were interviewed for the study identified a concern that children in single rooms called upon them more often to meet their social needs. This has important implications for children with medulloblastoma, as they are required to stay in single isolation rooms to protect their compromised immune systems. It is therefore essential to devise ways to increase the social experiences of these children while ensuring that they are protected physically. Information and communication technology (ICT) is a suitable and timely solution to offer these children means to socialize and remain safe.

There has been a rapid increase in the use of ICTs such as the Internet and cell phones among children and youth (Lenhart et al., 2008; Valcke et al., 2011). ICT use is pervasive among socio-demographically diverse populations of youth. Research indicates that $98 \%$ of Canadian youth access the Internet and communication technologies such as social networking sites on a daily basis (Cassidy et al., 2009; Mishna et al., 2010). In the U.S. $92 \%$ of adolescents between the ages of 13 and 17 years went online daily (56\% went online several times per day), while $91 \%$ of youth were online sometimes (Lenhart et al., 2015). Among the benefits for youth of the recent advances in ICTs include numerous and unprecedented possibilities to facilitate education, social communication, development, health and mental health (Ammerlaan et al., 2015; Areepattamannil \& Khine, 2017; Strom \& Strom, 2012). According to Valcke et al. (2011, p. 1293), "social networking dominates all types of Internet usage from 13 years on," and these sites have been found to provide access to a greater network of peers compared to other online media (Bender et al., 2008). ICTs provide a unique and innovative solution for children and adolescents who are isolated in hospital to maintain social and academic contact. While research on ICT use within hospital settings is growing, much of the focus tends to be on the creation and use of structured ICT tools and apps. Maor and Mitchem (2015) conducted a systematic review examining 14 studies published between 1999 and 2014 on the social and educational impact of ICT use among hospitalized youth. Of these 14 studies, 13 examined specific ICT tools (e.g., "StarBright"), designed to connect hospitalized children with each other (Battles \& Wiener, 2002; Hazzard, Celano, Collins, \& Markov, 2002; Holden, Bearison, Rode, Rosenberg, \& Fishman, 1999; Nicholas, Darch, McNeill, \& Koller, 2007), or programs like "Zora", a web-based virtual community meant to provide online support for transplant survivors (Bers, 2009; Bers et al., 2010; Cantrell, Fischer, Bouzaher, \& Bers, 2010). Only Nisselle, Hanns, Green, and Jones (2012) explored the extent to which hospitalized children utilized laptops and other personal ICTs to access technologies such as gaming, social networking, and Skype to remain socially and academically connected to peers. Results of this study documented the ways hospitalized children utilized laptops, largely for playing games and completing schoolwork. Notably, hospital and government policies restricted the use of social messaging sites for these patients. Despite these policies, patients, particularly adolescents, reported navigating around these restrictions to access social networking sites. Although the only study included in this review to explore open-ended ICT use, Nisselle et al.'s (2012) study included a sample of children admitted to hospital for a wide range of diagnoses including eating disorders, neurology, cystic fibrosis, and cancer (type not specified). More recent research that similarly examined the open use of ICTs for hospitalized children and youth also included a sample of children with varying diagnoses including juvenile arthritis, chronic kidney disease, as well as cancer (Nicholas \& Chahauver, 2017). Thus, research is lacking on the unique experience of children and adolescents with a malignant brain tumor.

While children and adolescents who undergo treatment for a malignant brain tumor are vulnerable to disruptions in their social and academic development, little is known about the isolation from children's perspectives. The one systematic review in this field of research concluded that there is a need for more robust exploration of children's experience of isolation directly from their perspectives (Austin et al., 2013). Due to the current global COVID-19 pandemic, it is uniquely timely to better understand the impact of isolation on children's mental health (Liu, Bao, Huang, Shi, \& Lu, 2020). The purpose of the current study, through the voices of children and adolescents with a malignant brain tumor, is to gain insight into the hospital isolation experience, as 
Table 1 Participants demographics

\begin{tabular}{llclllll}
\hline Pseudonym & Identified gender & $\begin{array}{l}\text { Age at } \\
\text { diagno- } \\
\text { sis }\end{array}$ & $\begin{array}{l}\text { Age at time } \\
\text { of interview }\end{array}$ & $\begin{array}{l}\text { Country } \\
\text { of origin } \\
\text { child }\end{array}$ & $\begin{array}{l}\text { Country of origin } \\
\text { mother }\end{array}$ & $\begin{array}{l}\text { Country of origin } \\
\text { father }\end{array}$ & $\begin{array}{l}\text { Time of treatment: } \\
\text { Before or after inception } \\
\text { of wireless capabilities } \\
\text { introduced in hospital }\end{array}$ \\
\hline Hannah & Female & 7 & 12 & Canada & Canada & Italy & Before live access \\
Aaron & Male & 14 & 22 & Canada & United States & United States & Before live access \\
Caiden & Male & 9 & 10 & Canada & Canada & Canada & After live access \\
Bennett & Male & 7 & 12 & Canada & Canada & Canada & Before live access \\
Samuel & Male & 14 & 16 & Canada & Mexico & Mexico & After live access \\
Matthew & Male & 7 & 12 & Canada & Canada & Guyana & Before live access \\
Aasia & Female & 8 & 12 & Canada & Afghanistan & Afghanistan & Before live access \\
Tyler & Male & 10 & 17 & Canada & Canada & Canada & Before live access \\
\hline
\end{tabular}

well as to better understand the use and impact of ICTs as a possible bridge for contact.

\section{Study Design}

A database maintained by the neuro-oncology program at a large urban children's hospital was consulted to generate a list of all patients with medulloblastoma who were currently being treated or had been treated with Protocol SJMB03 (See Gajjar et al., 2011). This treatment protocol was selected due to the lengthy hospital isolation required as part of this treatment regime, which includes surgery, radiation, and consecutive cycles of high-dose chemotherapy and autologous stem cell transplant. Participants on the list who met the following inclusion criteria were contacted: (1) they were patients of the neuro-oncology program at this hospital; (2) they had a diagnosis of medulloblastoma; (3) they were currently receiving treatment or had completed this treatment protocol; (4) they were between the ages of 7 and 18 at the time of starting treatment; (5) informed consent was obtained; (6) they did not present with severe cognitive or communication impairments as determined by being in a regular classroom; (7) they were English speaking; and (8) participants were not acutely ill. Age seven was selected as the earliest age of inclusion to ensure participants would have attended school prior to hospitalization.

Of a possible 46 patients, 30 met the required inclusion criteria. Sensitivity was maintained throughout the recruitment and data generation stages through frequent communication with the lead neuro-oncologist to ensure patients' health had not deteriorated during the study period. The rationale for contacting children who were currently completing treatment and those who had already completed treatment was to not limit the number of potential participants. There was no time restriction on the length of time when patients had completed treatment. Consequently, the difference between time of treatment and time of interview ranged from 1 to 8 years.

Upon receipt of approvals from the research ethics boards at the affiliated hospital and University, a recruitment package was mailed to all 30 possible participants. As part of the recruitment strategy, follow-up phone calls were made to all potential participants who had received a mailed invitation package. Of the 30 potential participants, eight agreed to participate, eight were never reached/calls were not returned, four had outdated contact information, three had relapsed and one child had died. Parents of six potential respondents declined participation citing reasons such as "trying to live a normal life now and not wanting to go back there", "wanting to forget" and "too much school work". Of those who were interested in participating, consent was received directly from those 13 and older, while combined assent and parental consent was obtained for those 12 and under.

Eight participants took part in interviews either in person at a mutually convenient location, or via telephone from the participants home. All participants had completed their treatment protocol at the time of interviews. Table 1 provides demographic information of participants. Participants ranged in age from 7 to 14 at the time of diagnosis and treatment, with ages ranging from 12 to 22 at the time of interview. Two participants identified as female, and six as male. To reach the depth required for an interpretive phenomenological design whereby the participant "tells their own story, and the interviewer listens" (Smith, Flowers, \& Larkin, 2009, p. 57), second interviews were scheduled and conducted with all eight participants during which new questions were asked and previous responses expanded and/or clarified. Children were asked to talk about their experience of staying in hospital isolation for their treatment. To contextualize the interview and aid subsequent analysis, reflexive memos were created, and notes were made on the interactions with the participant following each interview.

Each interview was audio-recorded and transcribed by members of the research team. Following Smith and 
colleagues' (2009) approach to interpretive phenomenological analysis, one transcript was analyzed in detail before incorporating others, thereby first creating preliminary notes before working up to more general categorization or theorization (Smith, Jarman, \& Osborn, 1999). This was carried out using close, line-by-line analysis of each participant's interview (Smith et al., 1999). Transcripts were read and reread to become as familiar as possible with the accounts. Initial notes were made, followed by a list of emerging themes based on dialogue between the researchers as a more interpretive account was being developed (Smith et al., 1999). This process was repeated for each subsequent interview, until a consolidated list of master themes for the group of all participants was created. The use of supervision, collaboration, and an audit trail of raw data and emergent themes amongst the research team allowed for the marrying of interpretations of the coded data, past knowledge about what it might mean for participants to have these experiences, and the impact of context, all of which enhance the quality of IPA design (Smith et al., 2009).

\section{Results}

Children and adolescents recounted their experiences in isolation while undergoing treatment for a malignant brain tumor. Three prevailing themes emerged: (1) the transformational power of a cancer diagnosis, and the deepening of child-adult relationships; (2) variance in ICT use while in hospital isolation to maintain social and academic connections; and (3) ICT as a promising bridge back to school. A fuller description of the themes is provided below.

\section{Transforming Children and Relationships}

Overall, participants reported an ongoing sense of loss related to their childhood, characterized by having to spend most of their time with adults, namely their parents and hospital staff. Although the children and adolescents reported feeling they had missed out on their childhood, all but one of the participants considered their time in isolation to be a positive experience, which allowed them to grow closer with their parents, and to develop a maturity beyond their years. Aaron $(14,22)^{1}$ for example, noted, "I really missed out on my teenage years because I was sick". For him, "it [treatment] was very isolating because kids didn't know how to process it, like my peers, they didn't know how to approach the situation. It was difficult. I felt largely at the time abandoned by them". In place of his friends, Aaron (14,

\footnotetext{
$\overline{1}$ Brackets denote age at diagnosis followed by age at time of research interview.
}

22) reported, "It got to the point where I wasn't thinking too much really about my friends, just about living, and I had everyone that I needed there [his parents]". Aaron $(14,22)$ further talked about the important role that staff on the unit played, stating, "I do remember a lot of the nurses and a lot of the doctors and a lot of the cleaners and everything were exceptionally nice people. I remember one very kind nurse in particular, she just talked to me". According to Aaron $(14,22)$, "You go through this cancer and you come out and you're not the same person...I don't know if I was more mature, but I definitely had a different way of looking at life than others. I'd like to say you appreciate life more. You try to appreciate life more and you view it as much more, what's the word, fragile".

Another youth Samuel $(14,16)$ expressed having longed to spend time with peers his own age: "It was hard at points because I wanted to be around someone my own age to talk about normal things and not be part of this hospital setting... Being around adults and parents, it threw me off my childhood". On the other hand, he too noted a shift as he progressed through the treatment process stating, "It was hard at first [not being able to see friends in person] but then it didn't really bother me. My family was there so that was all I needed". Moreover, he spoke about the positive impact of the staff on the unit, in place of his friends, during treatment: "One nurse really made my spirits brighter...It was as if I had a friend right there". For Samuel $(14,16)$, the treatment experience resulted in newfound strength, "Most people that are my age they experience things but nothing so hard such as having cancer or going through cancer, and throughout my stay on the isolation unit it was tough and like when I got out of it I felt stronger, I felt wow I actually did this and it just gave me this entirely new perspective on everything".

Another participant, Tyler $(10,17)$, similarly focused on the connection he made with his parents during this time of isolation away from his peers. "I can see even now that I have a closer relationship with my parents than any of my peers do. My parents are my friends because in my time of need, they were the people that were there for me the most. And that really strengthened our bond." He continues, "A lot of people take their parents for granted and I look at my parents as my best friends in the world. People that are going to be there for me as long as I live. And they would do anything for me. They gave up everything in their life to be with me, and that, a lot of people wouldn't do that". Tyler $(10,17)$ describes the maturity he feels as a result of missing out on his childhood for something as "traumatic" as cancer. He notes,

I feel like I'm at an adult level, 'cause that's pretty much everyone I spent time with. I think that I see the world differently; I' $m$ certainly experienced beyond my age. 
Matthew $(7,12)$, one of the participants, described his stay in hospital isolation as a positive experience as it allowed him to spend time with his father, which he felt might not have been possible had he not been sick in hospital: "My best memory from hospital is watching movies with my dad, because at home he's like 'oh no, I have work to do' and then he just runs straight up to the computer and does work. It felt nice having him with me". Matthew $(7,12)$ also highlighted the important role of hospital staff, noting, "One of the doctors used to say I was her "shining light"". He attributed his hospital treatment to his newfound ability to create relationships, such as with the staff, as he felt he became "more confident" during treatment.

In contrast to the other participants, Aasia $(8,12)$ depicted the experience as 'lonely' and 'boring', and as one in which she missed her friends. She did not regard the hospital as a community and did not report a deepening of her relationship with her parents, nor any feelings of transformation. She stated, "I felt bad there, I was alone there, I had no one to talk to, and it was boring there, I had nothing to do". About being with her parents every day, she said "it gets boring because I was with the same people every day". Of importance to note, Aasia $(8,12)$ 's parents requested the medical team not to disclose her cancer diagnosis to her, and by request of her parents, this writer was asked not to use the word cancer throughout the research interview.

\section{Hospitalization in a Digital World}

Participants varied greatly in their ICT use. Most participants reported rarely using ICTs, and if they did, it was most often for playing games. Matthew $(7,12)$ for example stated that he did not use a computer regularly, but when he did it was a hospital computer in a clinic pod, which he also used to play games. Aasia $(8,12)$ brought in her own laptop to "play games and listen to music", as did Tyler $(10,17)$, who played games on his laptop. Aaron $(14,22)$ reported the least use of ICTs, stating, "I had almost no contact. Maybe I got one or two phone calls the entire time...I don't recall much media stuff at all. I didn't have Facebook or anything like that. I didn't have a cell phone. I didn't have a computer. All I had was the phone in the room."

Both Bennett $(7,12)$ and Hannah $(7,12)$ reported using ICTs mostly to play games, but also to "virtually attend" significant family events while isolated in hospital. Bennett $(7,12)$ used ICT's to be with his family at Christmas, and Hannah $(7,12)$ reported feeling "very sad" about missing her brother's birthday, so she used the computer to send and receive pictures related to this milestone.

Samuel $(14,16)$ and Caiden $(9,10)$ reported frequent ICT use while in hospital. Samuel $(14,16)$ stated that his brother would bring in his laptop often, and together they would go on Facebook. Samuel $(14,16)$ talked about an online group that his brother created to support Samuel $(14,16)$ throughout his treatment:

Seeing all of these people that couldn't visit but still supported me, it made me stronger. I felt I have these people behind me, I have to push for them. I'll get through this.

When asked to compare the online support from peers to face-to-face interactions, Samuel $(14,16)$ reported: "It would have been different to be able to speak to them one on one, but I still understood what they were saying...the messages were enough". After completing treatment and returning to school, Samuel $(14,16)$ learned that his classmates were using technology to chronicle significant school events for him:

It was as if I was there. They videotaped part of the dances, part of the activities, and part of the school trip they went to...At the end of the video they had everyone say something to me. Just wishing me to keep fighting, never give up...I had no idea they were doing it and it made me think wow they didn't forget about me.

Like Samuel $(14,16)$, Caiden $(9,10)$ used ICTs while in hospital for treatment to maintain contact with his classmates. Caiden $(9,10)$ had access to a webcam that was set up in his hospital room which allowed him to logon in the morning and talk to his class. Consequently, when Caiden $(9,10)$ returned to school, he was familiar with his teacher and classmates, and vice versa. Using the webcam and a smartboard at school, Caiden $(9,10)$ 's teacher included him in all lesson plans and social activities every day, allowing him to "pass" if he did not want to participate. The students in Caiden $(9,10)$ 's class passed around handheld microphones to communicate with him.

\section{ICTs as a Bridge Back to School}

Returning to school after their hospitalization emerged as an important theme for the participants. Most striking was the impact of their treatment on their social experiences. Hannah $(7,12)$ said, "I was nervous", I was worried, "nobody would recognize me...my friends didn't remember me. Because when I went back to school I went into the classroom and no one remembered who I was. I was very sad". Bennett $(7,12)$ similarly talked about struggling upon his return to school, saying that both he and school felt "different". He stated, "School felt different. I feel like I'm not the same as I used to be. It's just people treat me different and stuff, they don't treat me the best".

Aaron $(14,22)$ described struggling socially upon returning to school, noting "the hardest time was not treating the 
cancer, it's post-treatment". Aaron $(14,22)$ attributes this shift in social experiences and closeness with his friends to the changes that occurred in him both physically, and in terms of his personality as a result of his treatment:

I left in grade 9 and I missed all of grade 10 and when I came back in grade 11 not only did I not have contact with my friends, but it was so long that a lot of the kids changed...I went back there after treatment basically emaciated with a hat that I didn't want to take off because I was bald, with a cane and with orthotics up to my knees. I couldn't be who I was.

Aaron $(14,22)$ recounted that his struggle with his return to school and reunification with peers affected him to such a degree that he considered suicide.

Aasia $(8,12)$ similarly described struggling with her return to school post isolation for treatment. Like Aaron (14, 22), she noted having had many friends prior to entering hospital for treatment, and not having any when she returned to school. "I used to have a lot of friends.... and now I have no friends... now I don't want to go to school because I have nothing to do because I have no friends and I feel angry, just like no one talks to me and it's like no one likes me in my school". Matthew $(7,12)$ likewise reported struggling socially after returning to school following isolation in hospital, explaining, "It's been hard to make new friends". He too noted the impact of his loss of physical ability on his capacity to make and keep friends, saying, "The boys were on sports teams and I couldn't do a lot of those things, I wasn't rehabbed enough for it, I couldn't keep up".

Of the eight participants, three described having a range of positive social experiences returning to school following isolation in hospital for treatment. Although Caiden $(9,10)$ missed nine consecutive months of school and described similar physical changes as did the other participants (e.g. losing his hair), he depicted having a seamless transition to school, stating that everything felt "the same" and that everyone treated him "the same". Similarly, Samuel (14, 16) reported that he was "not worried socially" about his return to school, explaining that although "my physical ability isn't there, socially, my friends still are". He reported that he knew his friends at school "always had my back. And I was happy to be back with them". Although Tyler (10, 17) felt "socially awkward" when he returned to school, he reported that "friendship-wise it basically took off where it left off...it felt like time hadn't really changed anything...it probably changed me but I just didn't really notice”. Despite not maintaining contact with his peers during treatment, Tyler $(10,17)$ reports knowing they supported him. Tyler $(10,17)$ explained that he is from a very small town, and that the school and community often held fundraisers in his honour: "Everybody kind of knew what I was going through and everyone that fundraised in the school had posters up everywhere for me. It was really nice. The whole school and community recognized what I was going through so that was good".

\section{Discussion}

This exploratory study addresses an extant gap in the literature focusing on children and adolescents' experience of hospital isolation due to their cancer treatment. Providing social opportunities for hospitalized children and youth has been associated with positive outcomes including decreased stress and improved well-being (Alvarez et al., 2020; Dilani, 2000; McLaughlan, 2018). Such opportunities include informal support gained through shared accommodations, and/ or creating physical spaces that promote interaction such as game rooms, music rooms, and/or cafés (Curtis \& Northcott, 2017; McLaughlan, 2018). Recent research findings conducted by Alvarez et al. (2020) emphasize the importance of these social experiences, noting "the clinical benefits of isolation procedures may be outweighed by how negatively isolation is experienced by patients, particularly when the patients are children" (pg. 414). While the benefits of social experiences for hospitalized children have been well-documented, children and youth undergoing treatment for medulloblastoma are not afforded these opportunities due to their required protective isolation. When removing children from their typical environments and social experiences therefore, priority must be given to bridging isolation particularly in medically fragile populations such as children with medulloblastoma. Findings from this study highlight ICTs as a bridge for this gap to support peer development.

During the school-age and adolescent phases of development, children and adolescents typically spend significantly more time at school, with peers, and participating in extracurricular activities, thus moving away from family. Because illness required the participants to be physically isolated in hospital for significant periods of time, however, they spent much of this time in hospital with their parents and other adult caregiver figures such as healthcare staff. A striking finding is that most of the children and adolescents reported this shift towards parents and adult caregivers as a significant and positive experience.

Attachment theory emphasizes the salience of the parent-child relationship as an evolutionary means of survival (Bowlby, 1982; Cassidy, 2016; Tacon, 2002). To be securely attached, a child must be confident in their caregiver's availability and responsiveness (Bowlby, 1973, 1979). During periods of perceived threat, the attachment system regulates a sense of security and protection by motivating closeness to an attachment figure, typically a parent (Tacon, 2002). Several studies with both humans and animals have documented the power of the attachment system to facilitate 
strong relational bonds that promote survival (Gunnar, Brodersen, Nachmias, Buss, Rigatuso, 1996; Harlow, 1958; Lorenz, 1935). As children age, the intensity and frequency of their attachment behaviour with their caregiver naturally declines, however this shift does not reduce the attachment bond (Bowlby, 1979). Findings of the current study are consistent with these theoretical underpinnings of attachment theory. Of the eight participants, seven described the shift towards parents and adult caregivers as positive, noting that hospital isolation allowed them to grow closer to their parents. Although most of the children initially reported a strong desire to be with their peers, as their treatment progressed and isolation continued, this desire decreased, and their wish to be with their parents increased. While this shift from peers to parents' veers from the typical developmental trajectory, it aligns with attachment theory; as perceived threats increase, children and adolescents have a universal need to seek close proximity with their caregiver (Prior \& Glaser, 2006). Except for one participant, all others reported how meaningful it was for them that their parents dropped their external commitments to live at the hospital with them for lengthy periods of time. This is consistent with the literature, as children depend upon the physical closeness as well as emotional availability of their attachment figure, particularly when they are ill (Bowlby, 1979).

In addition to this newfound connection with their parents, many children and adolescents in the study came to feel close with hospital staff. Participants referred to all types of staff, including doctors, nurses, clowns, and cleaners. These findings highlight that when isolated in hospital for significant periods of time, the children and adolescents were focused on feeling connected with the caring adults around them. This finding is supported by research in child development, which highlights that children seek connection as a means of protection, which creates a sense of attachment (Barber \& Schluterman, 2008; Willard, Russell, Long, \& Phipps, 2019). Research with nurses working on a bone marrow transplant unit that requires patient isolation documented similar findings, with nurses reporting feelings of closeness and friendship with many children and families with whom they work, citing a unique shared experience during a very isolating and intense treatment journey (Morrison \& Morris, 2017).

While the majority considered having to spend most of their time with adult figures as a positive experience, participants concurrently reported feeling that they were missing out on their childhood and having to mature quickly. All but one participant recounted their experience as transformational, giving them a "new perspective" on what is important in life. As a result of their hospital isolation experience, participants declared feeling different from their peers with respect to priorities. They described a shift away from things that would otherwise be deemed important for same age peers such as "partying", and rather, focussed more on "being alive". This adjustment in age-related priorities and the participants' depiction of their transformational experience aligns with the concept of resilience, which refers to positive adaptation following adversity (Fletcher \& Sarkar, 2013). Research has documented an association between attachment and resilience, as secure attachment is a core factor in positive adaptation to adverse experiences (Rasmussen $\&$ Storebo, 2019). In the face of trauma and loss, secure attachment is a protective factor that can predict positive adaptation to challenging and potentially life-threatening conditions (Tosone, Minami, Bettmann, \& Jasperson, 2010). Although attachment styles were not assessed as part of this study, it highlights the reliance of critically ill children on parents and caregivers during isolation, and the important role that parents and other adult figures have in providing support. Resilience is not an innate characteristic (Rutter, 2007) and rather, is facilitated through the formation of strong and stable relationships with others (Rasmussen \& Storebo, 2019).

Only one participant did not characterize her experience as positive; in contrast, she described persistently longing for her peers throughout her treatment. Although it is not possible to assess the reasons for this difference, it is important to note that she was the only child who, at her parents' request, was not explicitly told her brain tumor was cancer, neither during treatment nor throughout the time of the current research. It is possible that lack of awareness of the life-threatening nature of one's diagnosis could influence hospital isolation experiences. In adolescent cancer survivors, research has pointed to an association between greater perceived treatment severity and the extent to which the youth felt their life was threatened, with post-traumatic growth, which refers to positive interpretations and meaning attributed to a traumatic experience (Barakat, Alderfer, \& Kazak, 2006). There is therefore a need to better understand the connection between full disclosure of a cancer diagnosis and its impact on the youth patients' adjustment both during and after treatment. Since full disclosure is against the moral norms of some cultures, addressing this issue must be carried out in a culturally sensitive and collaborative manner (Pergert \& Lutzen, 2012).

Another important finding is that participants' ICT use while in hospital isolation varied greatly. The two participants who were in hospital after it went "live" with wireless technologies used ICTs extensively to maintain connections socially and academically, whereas the other six participants used ICTs minimally, and when they did it was to play games or to virtually attend a family event. The two participants with the greatest access to ICTs described the most positive outcomes transitioning to school following isolation in hospital, reporting it was as if they had never left. Conversely, the six participants who did not have access 
to wireless technologies in hospital, and who reported rarely utilizing ICTs described struggling with their return to school. Despite limited access to ICT use, one participant reported maintaining a very strong connection to his small tight-knit community while in hospital, through methods such as phone calls and pictures, as well as community rallies and fundraisers in support of his health. This finding suggests ways other than ICTs to maintain connection and support for hospitalized children and adolescents isolated from peers, their classroom, and their community.

Findings from the current study support the use of ICTs by hospitalized children and adolescents, both to maintain social connections with peers and to support them academically as they transition back to their classroom. Two participants reported changes in their physical appearance due to treatment, and both described very different experiences upon returning to school. One participant discussed physical changes he endured, which he felt prevented his peers from accepting him upon his return to school. This participant did not access ICTs to remain in contact with his classmates throughout his treatment, which contrasts with the other participant who reported physical changes but did maintain daily contact with his classmates via ICTs. While this participant reported similar physical changes (e.g., baldness) during isolation, his classmates were able to watch and notice the implications of his treatment via a webcam daily. This utilization of the webcam to connect him with his class, therefore, may have aided in a smooth and positive transition back to school as his peers were familiar with his physical changes. Along the same lines, another participant who rarely utilized ICTs, reported feeling nervous that she would not be recognized upon her return to school, noting that her worries were actualized when indeed no one remembered her.

Research regarding the use of ICTs and its impact on the psychosocial health and functioning of children and adolescents has produced mixed outcomes (Park \& Lee, 2018). Some empirical studies include findings of increased mental health problems such as depression and anxiety amongst adolescent ICT users (Belanger, Akre, Berchtold, \& Michaud, 2011; Ko, Yen, Liu, Huang, \& Yen, 2009); while other research points to the use of ICTs to promote communication and social relationships between youth (Bezinović, Roviš, Rončević, \& Bilajac, 2015). Unique to the current study was the focus on widespread, open ended ICT use among children and adolescents with a malignant brain tumor physically isolated in hospital for treatment. According to the results, those with the greatest ICT use for both social and academic connection reported struggling much less with their return to school post hospital isolation. As ICTs act as a bridge to maintain connection for children and adolescents, it is relevant and important to consider ICT use from an attachment theory lens. In the current study, one participant who was isolated in hospital prior to its use of wireless technology and who reported the least use of ICTs, stated that he felt "abandoned" by his peers, and that his return to school post-isolation was more difficult than dealing with the life-threatening cancer itself. He added that his return to school and feelings of rejection by peers was so significant that he considered suicide. It is possible that increased access to ICTs and thus academic and social connection, would have allowed this participant to maintain bonds with his peers and support his mental health. Research has documented that consideration of an attachment theory lens is critical to the study of suicide and social relationships, as fear of abandonment leads to increased anxiety as well as risk of suicidality (Ledgerwood, 1999). When individuals are without physical and/or emotional support, they are increasingly more vulnerable (Johnson, Makinen, \& Millikin, 2001). Notably, social relationships are only one factor that may have buffered the risk of suicidality that this participant was experiencing, as suicide can take place when social relationships are present if other factors such as depression exist (Fotti, Katz, Afifi, Cox, 2006). The ubiquitous use and nature of ICTs suggests that this type of contact is common (Pew Research Center, 2018). Nevertheless, it is important to understand the impact of such use, and the implications when use is not possible, to inform recommended strategies to ensure the well-being of youth in hospital isolation. Further research is needed to better understand the impact and perceptions of the peers and classmates at the other end of the ICT experience.

\section{Limitations}

Although the sample size utilized for this study is appropriate for an interpretive phenomenological design, continued exploration within this field would add value given that only a quarter of eligible participants agreed to participate. Due to the paucity of research that explores children's perspectives of hospital isolation, additional qualitative research is warranted to develop an evidence base to guide supports with this vulnerable population. Additionally, it is important to acknowledge that the database of potential participants consulted for this study included patients across a very large catchment area, thereby including a range of socio-economic status backgrounds. While from diverse geographic areas, all participant families were living in hospital and/or at the partnering support home for out-of-town families of critically ill children while children and youth were undergoing treatment. Another limitation is the large age range of participants. Although we were able to explore this experience across the spectrum of development, the small sample size precluded much comparison within age related clusters. Also, the inclusion criteria allowed for participation by those 
who completed treatment both prior to and after the inception of wireless capabilities in the hospital. A limitation as a result is that only two of the eight participants were in the hospital at a time of unlimited wireless access. Thus, there is more limited understanding of ICT use among this population, since the majority of the participants had limited access. Notwithstanding this limitation, including participants with varying levels of access allowed for comparison between these groups. Despite these limitations, study findings add critical information to a largely understudied topic of hospital isolation from the perspectives of children and youth.

\section{Implications for Social Work Practice}

Hospital social workers are a critical resource and support to parents of children with cancer (Shields et al., 1995). Given social work's long-standing premise of person-inenvironment (Zapf, 2009), hospital social workers are well positioned to support the interplay of relationships between children and their parents, peers, and hospital staff. Parents face an enormous task of meeting the physical and psychological needs of their child with cancer, alongside processing their diagnosis and its life-threatening implications (Desmond, 1980). Parents' well-being can be impacted and thus influence the attachment relationship, since parents who experience stress may struggle in their attunement and responsiveness to their child's needs (Keenan, Newman, Gray, \& Rinehart, 2016). Emphasizing the person-in-environment context, hospital social workers therefore play an integral role in supporting parents' grief, anger, sadness, and other feelings related to their child's diagnosis, to help them manage and respond to their child. Study findings indicated a shift towards parents as treatment progressed, highlighting the increasing need of parental support for them to support their children. Hospital social workers can further support positive relationships between children and parents by ensuring that parents are connected to social supports (i.e., extended family and friends) and community resources (Siegel, 1990).

A major finding of the current study was the importance of maintaining contact between children and their peers. As survival rates for children with brain tumors improve, supporting their quality-of-life during as well as post-treatment is critical (Willard, 2018). Children and adolescents isolated in hospital for treatment are not afforded the same social interactions that would occur outside the hospital. It is important to consider the use of ICTs as a promising tool to mitigate the effects of isolation both during treatment, as well as to support them as they transition back to school following isolation. One way to bridge this contact, which was supported by the findings, is to use technology to include children and youth in their everyday classroom. Social workers can assist with this process by minimizing barriers to ICT access for all hospitalized children and adolescents, as well as educating children and families on the safe and ethical use of ICTs.

Situated in an ecological understanding of person-inenvironment, as well as knowledge of developmental and attachment theories, hospital social workers can also help foster connections and relationships for children and adolescents isolated for treatment with hospital staff. Children and adolescents in this study described their relationship with hospital staff as significant and comforting. This is not uncommon, as "patients with serious illness derive a sense of security by forming strong, healing relationships with their providers" (Epner, Ravi, \& Baile, 2011, p. 1731). Recognizing the importance of this relationship, social workers can suggest strategies to facilitate this connection, while also providing education opportunities to staff highlighting their important contribution to the child's psychosocial context. Importantly, social workers are also sensitive to the cultural needs of children and families. Although we do not know why one participant did the least well during and after hospital isolation, it is important for social workers to be aware of the potential impact of full disclosure on children's understanding of the severity of their illness.

\section{Conclusion}

The current study highlights the convergence of two developmental processes; children and adolescents' need for attachment with their caregiver(s) when they experience a life- threatening illness, and their developmental need for growing autonomy and connections with peers. As children and adolescents' treatment progressed and isolation continued, their need for their primary attachment figure increased. Their developmentally appropriate need for autonomy and peer relationships re-emerged, however, as they completed treatment and transitioned from hospital isolation back to school. ICTs were a promising bridge to support this reconnection. This paper thus deepens our understanding of isolation experiences for children and adolescents', while also providing concrete strategies for hospital social workers to support the convergence of developmental and attachment needs.

While protective isolation in hospital is required to maintain the health of children and adolescents with a malignant brain tumor undergoing treatment, its impact cannot be ignored. Research with an adult population found that negative psychosocial effects from hospital isolation can begin in as little as 24 hours of isolation (Knowles, 1993). ICTs are a promising bridge to maintain connection and minimize the negative impacts of isolation for children and adolescents, and to 
support a positive transition back to school. Given the growing use of ICTs and access to mobile devices, in conjunction with the intensity and duration of isolation for treatment of a malignant brain tumor, the need for further research in this area is paramount.

During this time of the current COVID-19 pandemic, there is an urgent need to better understand isolation experiences for all people, and particularly for children and youth. After the Coronavirus disease 2019 (COVID-19) was declared a pandemic in March 2020 (Bruinen de Bruin et al., 2020), it was recommended worldwide that people isolate at home (Brooks, 2020). As a result, schools were closed and in many countries, children have been physically isolated from their peers for months. Researchers are currently prioritizing the need to better understand the psychological impact of such quarantine for people of all ages to inform policy and strategies to address isolation (Brooks, 2020). Although quarantine, which is the separation and restriction of people who may have been exposed to a contagious disease (CDCP, 2017), and isolation, which is the separation of people who have already been diagnosed with a disease from others who are not sick, differ in their definitions, the terms are often used interchangeably (Brooks, 2020). The current study provides timely and significant insights into the experiences of hospital isolation for children and adolescents, as well as considerations to promote relationships and connection, while facilitating a smooth transition as they return back to school.

Acknowledgements This study was funded by a grant from the Social Sciences and Humanities Research Council of Canada.

\section{References}

Abad, C., Fearday, A., \& Safdar, N. (2010). Adverse effects of isolation in hospitalised patients. A systematic review. Journal of Hospital Infection, 76, 97-102.

Alvarez, E. N., Pike, M. C., \& Godwin, H. (2020). Children's and parents' views on hospital contact isolation: A qualitative study to highlight children's perspectives. Clinical Child Psychology and Psychiatry, 25(2), 401-418.

Ammerlaan, J. J., Scholtus, L. W., Drossaert, C. H., van Os-Medendorp, H., Prakken, B., Kruize, A. A., \& Bijlsma, J. W. J. (2015). Feasibility of a website and a hospital-based online portal for young adults with juvenile idiopathic arthritis: Views and experiences of patients. JMIR Research Protocols, 4(3), e102.

Areepattamannil, S., \& Khine, M. S. (2017). Early adolescents' use of information and communication technologies (ICTs) for social communication in 20 countries: Examining the roles of ICTrelated behavioral and motivational characteristics. Computers in Human Behavior, 73, 263-272.

Austin, D., Prieto, J., \& Rushforth, H. (2013). The child's experience of single room isolation: A literature review. Nursing Children and Young People, 25(3), 18-24.

Barakat, L. P., Alderfer, M. A., \& Kazak, A. E. (2006). Posttraumatic growth in adolescent survivors of cancer and their mothers and fathers. Journal of Pediatric Psychology, 31(4), 413-419.
Barber, B. K., \& Schluterman, J. M. (2008). Connectedness in the lives of children and adolescents: A call for greater conceptual clarity. Journal of Adolescent Health, 43, 209-216.

Battles, H. B., \& Wiener, L. (2002). STARBRIGHT World: Effects of an electronic network on the social environment of children with life-threatening illnesses. Children's Health Care, 31(1), 47-68.

Belanger, R. E., Akre, C., Berchtold, A., \& Michaud, P. A. (2011). A U-shaped association between intensity of Internet use and adolescent health. Pediatrics, 127(2), e330-e335.

Bender, J. L., O'Grady, L., \& Jadad, A. R. (2008). Supporting cancer patients through the continuum of care: A view from the age of social networks and computer-mediated communication. Current Oncology, 15(2), S42-S47.

Berlin-Romalis, D., \& Doyle, J. (2010). While your child is in the hospital. Retrieved October 20, 2011 from http://www.about kidshealth.ca/En/ResourceCentres/BloodandMarrowTransp lant/WhileYourChildIsInHospital/Pages/default.aspx

Berrera, M., Shaw, A. K., Speechley, K. N., Maunsell, E., \& Pogany, L. (2005). Educational and social late effects of childhood cancer and related clinical, personal, and familial characteristics. Cancer, 104(8), 1751-1760.

Bers, M. U. (2009). New media for new organs: A virtual community for pediatric post-transplant patients. Convergence, 15(4), 462-469.

Bers, M. U., Beals, L. M., Chau, C., Satoh, K., Blume, E. D., DeMaso, D. R., \& Gonzalez-Heydrich, J. (2010). Use of a virtual community as a psychosocial support system in pediatric transplantation. Pediatric Transplant, 14(2), 261-270.

Bezinović, P., Roviš, D., Rončević, N., \& Bilajac, L. (2015). Patterns of Internet use and mental health of high school students in Istria County Croatia: Cross-sectional study. Croatian Medical Journal, 56(3), 297-305.

Bi, Y., Ma, L., Yuan, F., \& Zhang, B. (2016). Self-esteem, perceived stress, and gender during adolescence: Interactive links to different types of interpersonal relationships. The Journal of Psychology, 150(1), 36-57.

Bowlby, J. (1960). Separation anxiety. International Journal of Psychoanalysis, 41, 89-113.

Bowlby, J. (1973). Attachment and loss. Vol. 2: Separation, anxiety and anger. Hogarth.

Bowlby, J. (1979). The making and breaking of affectional bonds. Tavistock.

Bowlby, J. (1982). Attachment and loss: Retrospect and prospect. American Journal of Orthopsychiatry, 52(4), 664-678.

Bowlby, J., \& Robertson, J. (1952). A two-year-old goes to hospital. Proceedings of the Royal Society of Medicine, 46, 425-427.

Broeder, J. L. (1985). School-age children's perceptions of isolation, after hospital discharge. American Journal of Maternal and Child Nursing, 14(3), 153-174.

Brooks, S. K. (2020). The psychological impact of quarantine and how to reduce it: Rapid review of the evidence. Lancet, 395, 912-920.

Bruinen de Bruin, Y., Lequarre, A.-S., McCourt, J., Clevestig, P., Pigazzani, F., Jeddi, M. Z., Colosio, C., \& Goulart, M. (2020). Initial impacts of global risk mitigation measures taken during the combating of the COVID-19 pandemic. Safety Science, 128, 104773.

Cantrell, K., Fischer, A., Bouzaher, A., \& Bers, M. (2010). The role of e-mentorship in a virtual world for youth transplant recipients. Journal of Pediatric Oncology Nursing, 27(6), 344-355.

Cassidy, J. (2016). The nature of the child's ties. In J. Cassidy \& P. R. Shaver (Eds.), Handbook of attachment: Theory, research, and clinical applications (3rd ed., pp. 3-25). The Guilford Press.

Cassidy, W., Jackson, M., \& Brown, K. (2009). Sticks and stones can break my bones, but how can pixels hurt me? Students' 
experiences with cyber-bullying.School Psychology International, 30(4), 383-402.

CDCP Centers for Disease Control and Prevention. (2017). Quarantine and isolation. https://www.cdc.gov/quarantine/index.html. Accessed January 30, 2020.

Cohen, E., Austin, J., Weinstein, M., Matlow, A., \& Redelmeier, D. A. (2008). Care of children isolated for infection control: A prospective observational cohort study. Pediatrics, 122(2), e411-e415.

Curtis, P., \& Northcott, A. (2017). The impact of single and shared rooms on family-centred care in children's hospitals. Journal of Clinical Nursing, 26(11-12), 1584-1596.

Desmond, H. (1980). Two families: An intensive observational study. In J. Kellennan (Ed.), Psychological aspects of childhood cancer (pp. 100-127). Charles C Thomas.

Desjardins, L., Barrera, M., Schulte, F., Chung, J., Cataudella, D., Janzen, L., Bartels, U., \& Downie, A. (2019). Predicting social withdrawal, anxiety and depression symptoms in pediatric brain tumor survivors. Journal of Psychosocial Oncology, 37(1), 22-36.

Dilani, A. (2000). Psychosocially supportive design-Scandinavian health care design. World Hospitals and Health Services, 37, 20-24.

Epner, D. E., Ravi, V., \& Baile, W. F. (2011). When patients and families feel abandoned. Supportive Care in Cancer, 19, 1713-1717.

Erikson, E. H. (1959). Identity and the life cycle: Selected papers. International University Press.

Fletcher, D., \& Sarkar, M. (2013). Psychological resilience: A review and critique of definitions, concepts, and theory. European Psychologist, 18(1), 12-23.

Fotti, S. A., Katz, L. Y., Afifi, T., \& Cox, B. (2006). The associations between peer and parental relationships and suicidal behaviors in early adolescents. The Canadian Journal of Psychiatry, 51(11), 698-703.

Foulkes, L., \& Blakemore, S.-J. (2018). Studying individual differences in human adolescent brain development. Nature Neuroscience, $21(3), 315-323$.

Gajjar, A. (2011). Treatment of patients with newly diagnosed medulloblastoma, supratentorial primitive neuroectodermal tumor, or atypical teratoid rhabdoid tumor. NIH: US National Library of Medicine. https://www.clinicaltrials.gov/ct2/show/NCT00 085202

Gammon, J. (1999). The psychological consequences of source isolation: A review of the literature. Journal of Clinical Nursing, 8, 12-21.

Gunnar, M. R., Brodersen, L., Nachmias, M., Buss, K., \& Rigatuso, J. (1996). Stress reactivity and attachment security. Developmental Psychobiology, 29, 191-204.

Guralnick, M., Neville, B., Hammond, M. A., \& Connor, R. T. (2007). The friendships of young children with developmental delays: A longitudinal analysis. Journal of Applied Developmental Psychology, 28(1), 64-79.

Harlow, H. F. (1958). The nature of love. American Psychologist, 13, 673-685.

Hartup, W. W., \& Laursen, B. (1991). Relationships as developmental contexts. In R. Cohen \& A. W. Siegel (Eds.), Context and development. Lawrence Erlbaum Associates Inc.

Hay, D. F., Payne, A., \& Chadwick, A. (2004). Peer relations in childhood. Journal of Child Psychology and Psychiatry, 45(1), 84-108.

Hazzard, A., Celano, M., Collins, M. H., \& Markov, Y. (2002). Effects of STARBRIGHT World on knowledge, social support, and coping in hospitalized children with sickle cell disease and asthma. Children's Health Care, 31(1), 69-86.

Hetherington, E. M., Parke, R. D., \& Schmuckler, M. (2003). Child psychology: A contemporary viewpoint. McGraw-Hill Ryerson Limited.
Holden, G., Bearison, D. J., Rode, D. C., Rosenberg, G., \& Fishman, M. (1999). Evaluating the effects of a virtual environment (STARBRIGHT World) with hospitalized children. Research on Social Work Practice, 9(3), 365-382.

Hollenbeck, A. R., Susman, E. J., Nannis, E. D., Strope, B. S., Hersh, S. P., Levine, M. D., \& Pizzo, P. A. (1980). Children with serious illness: Behavioral correlates of separation and isolation. Child Psychiatry and Human Development, 11, 3-11.

Hoppe-Hirsch, E., Renier, D., Lellouch-Tubiana, A., Sainte-Rose, C., Pierre-Kahn, A., \& Hirsch, J. F. (1990). Medulloblastoma in childhood: Progressive intellectual deterioration. Child's Nervous System, 6(2), 60-65.

Johnson, S. M., Makinen, J. A., \& Millikin, J. W. (2001). Attachment injuries in couple relationships: A new perspective on impasses in couples therapy. Journal of Marital and Family Therapy, $27(2), 145-155$.

Keenan, B. M., Newman, L. K., Gray, K. M., \& Rinehart, N. J. (2016). Parents of children with ASD experience more psychological distress, parenting stress, and attachment-related anxiety. Journal Autism Developmental Disorders, 46, 2979-2991.

Knowles, H. E. (1993). The experience of infectious patients in isolation. Nursing Times, 89, e53-e56.

Ko, C. H., Yen, J. Y., Liu, S. C., Huang, C. F., \& Yen, C. F. (2009). The associations between aggressive behaviors and Internet addiction and online activities in adolescents. Journal of Adolescent Health, 44(6), 598-605.

Koller, D. F., Nicholas, D. B., Salter Goldie, R., Gearing, R., \& Selkirk, E. K. (2006). When family-centered care is challenged by infectious disease: Pediatric health care delivery during the SARS outbreaks. Qualitative Health Research, 16(1), 47-60.

Krull, K. R., Hardy, K. K., Kahalley, L. S., Schuitema, I., \& Kesler, S. R. (2018). Neurocognitive outcomes and interventions in long-term survivors of childhood cancer. Journal of Clinical Oncology, 36(21), 2181-2189.

Laursen, B., \& Bukowski, W. M. (1997). A developmental guide to the organisation of close relationships. International Journal of Behavior Development, 21(4), 747-770.

Laxmi, V., \& Kadapatti, M. (2012). Analysis of parenting styles and interpersonal relationship among adolescents. International Journal of Scientific and Research Publications, 2(8), 1-5.

Ledgerwood, D. M. (1999). Suicide and attachment: Fear of abandonment and isolation from a developmental perspective. Journal of Contemporary Psychotherapy, 29(1), 65-73.

Lenhart, A., Arafeh, S., Smith, A., \& Macgill, A. (2008). Writing, technology and teens. Pew Internet \& American Life Project. http://www.pewinternet.org

Lenhart, A., Duggan, M., Perrin, A., Stepler, R., Rainie, L., Parker, K., \& Pew Research Center. (2015). Teens, social media \& technology overview. http://www.pewinternet.org/files/2015/04/PI TeensandTech_Update2015_0409151.pdf

Liu, J. J., Bao, Y., Huang, X., Shi, J., \& Lu, L. (2020). Mental health considerations for children quarantined because of COVID-19. The Lancet, Child \& Adolescent Health, 4(5), 347-349.

Lorenz, K. Z. (1935). Der Kumpan in der Umwelt des Vogels (The companion in the bird's world). Journal fur Ornithologie, 83, 137-213. (Abbreviated English translation published 1937 in Auk, 54, 245-273.)

Maor, D., \& Mitchem, K. J. (2015). Can technologies make a difference for hospitalized youth: Findings from research. Journal of Computer Assisted Learning, 31(6), 690-705.

McLaughlan, R. (2018). Psychosocially supportive design: The case for greater attention to social space within pediatric hospital. Health Environments Research \& Design Journal, 11(2), 151-162.

Meeus, W., Iedema, J., Maassen, G., \& Engels, R. (2005). Separationindividuation revisited: On the interplay of parent-adolescent 
relations, identity and emotional adjustment in adolescence. Journal of Adolescence, 28, 89-106.

Mishna, F., Cook, C., Gadalla, T., Daciuk, J., \& Solomon, S. (2010). Cyber bullying behaviors among middle and high school students. American Journal of Orthopsychiatry, 80(3), 362-274.

Morrison, C. F., \& Morris, E. J. (2017). The practices and meanings of care for nurses working on a pediatric bone marrow transplant unit. Journal of Pediatric Oncology Nursing, 34(3), 214-221.

Murray, J. S. (2000). Understanding sibling adaptation to childhood cancer. Issues in Comprehensive Pediatric Nursing, 23, 39-47.

Musiello, T., Platt, V., Plaster, M., Haddow, L., \& Ives, A. (2014). Dealing with cancer: The experiences of adolescents and young adults treated in adult hospitals in Western Australia. Journal of Adolescent and Young Adult Oncology, 3(1), 42-46.

Nesi, J., Choukas-Bradley, S., \& Prinstein, M. J. (2018). Transformation of adolescent peer relations in the social media context: Part 1-A theoretical framework and application to dyadic peer relationships. Clinical Child and Family Psychology Review, 21(3), 267-294.

Nicholas, B., \& Chahauver, A. (2017). Examining computer use by hospitalized children and youth. Journal of Technology in Human Services, 35(8), 1-15.

Nicholas, D. B., Darch, J., McNeill, T., \& Koller, D. (2007). Perceptions of online support for hospitalized children and adolescents. Social Work in Health Care, 44(3), 205-223.

Nisselle, A., Hanns, S., Green, J., \& Jones, T. (2012). Accessing flexible learning opportunities: Children's and young people's use of laptops in a paediatric hospital. Technology Pedagogy and Education, 21(1), 3-20.

Packer, R. J., Gurner, J. G., Punyko, J. A., Donaldson, S. S., Inskip, P. D., Stovall, M., Yasui, Y., Mertens, A. C., Sklar, C. A., Nicholson, H. S., Zeltzer, L. K., Neglia, J. P., \& Robison, L. L. (2003). Long-term neurologic and neurosensory sequelae in adult survivors of a childhood brain tumor: Childhood cancer survivor study. Journal of Clinical Oncology, 21, 3255-3261.

Park, S., \& Lee, H. (2019). Patterns of online activities and related psychosocial factors in adolescence: A latent class analysis. International Journal of Mental Health and Addiction, 17(4), $1147-1161$

Pergert, P., \& Lutzen, K. (2012). Balancing truth-telling in the preservation of hope: A relational ethics approach. Nursing Ethics, 19(1), 21-29.

Pew Research Center. (2018). A majority of teens have experienced some form of cyberbullying. Retrieved from http://www.pewin ternet.org/2018/09/27/amajority-of-teens-have-experiencedsome-form-of-cyberbullying/

Pfeifer, J. H., \& Berkman, E. T. (2018). The development of self and identity in adolescence: Neural evidence and implications for a value-based choice perspective on motivated behavior. Child Development Perspectives, 12(3), 158-164.

Powazek, M., Goff, J. R., Schyving, J., \& Paulson, M. A. (1978). Emotional reactions of children to isolation in a cancer hospital. Journal of Pediatrics, 92(5), 834-837.

Prior, V., \& Glaser, D. (2006). Child and adolescent mental health series. Understanding attachment and attachment disorders: Theory, evidence and practice. Jessica Kingsley Publishers.

Purssell, E., Gould, D., \& Cudleigh, J. (2020). Impact of isolation on hospitalized patients who are infections: Systematic review with meta-analysis. British Medical Journal, 10, e030371.

Rashid, H., Ridda, I., King, C., Begun, M., Tekin, H., Wood, J. G., \& Booy, R. (2015). Evidence compendium and advice on social distancing and other related measures for response to an influenza pandemic. Paediatric Respiratory Reviews, 16(2), 119-126.

Ramaswamy, V., Nor, C., \& Taylor, M. D. (2016). P53 and meduloblastoma. Cold Spring Harbour Perspectives in Medicine, 6(2), 1-9.
Rasmussen, P. D., \& Storebo, O. J. (2019). Attachment as a core feature of resilience: A systematic review and meta-analysis. Psychological Reports, 122(4), 1259-1296.

Robertson, J. (1958). Young children in hospitals. Basic Books.

Rubin, K. H., Chen, X., Coplan, R., Buskirk, A., \& Wojslawowicz, J. C. (2005). Peer relationships in childhood. In M. H. Bornstein \& M. E. Lamb (Eds.), Developmental science: An advanced textbook (5th ed., pp. 469-512). Erlbaum.

Russo, K., Donnelly, M., \& Reid, A. J. M. (2006). Segregation-The perspectives of young patients and their parents. Journal of Cystic Fibrosis, 5(2), 93-99.

Rutter, M. (2007). Resilience, competence, and coping. Child Abuse \& Neglect, 31, 205-209.

Schulte, F., \& Barrera, M. (2010). Social competence in childhood brain tumor survivors: A comprehensive review. Supportive Care in Cancer, 18, 1499-1513.

Shaver, P. R., Mikulincer, M., \& Feeney, B. C. (2009). What's love got to do with it? Insecurity and anger in attachment relationships. Virginia Journal of Social Policy \& the Law, 16, 491-513.

Shin, K. M., Cho, S.-M., Shin, Y. M., \& Soon Park, K. (2016). Effects of early childhood peer relationships on adolescent mental health: A 6-to-8 year follow-up study in South Korea. Psychiatry Investigations, 13(4), 383-388.

Shields, G., Schondel, C., Barnhart, L., Fitzpatrick, B. S., Sidell, N., Adams, P., Fertig, B., \& Gomez, S. (1995). Social work in pediatric oncology. Social Work in Health Care, 21(1), 39-54.

Siegel, K. (1990). Psychosocial oncology research. Social Work in Health Care, 15(1), 21-41.

Smith, J. A., Jarman, M., \& Osborn, M. (1999). Doing interpretive phenomenological analysis. In M. Murray \& K. Chamberlain (Eds.), Qualitative health psychology (pp. 218-240). SAGE Publications Ltd.

Smith, J. A., Flowers, P., \& Larkin, M. (2009). Interpretive phenomenological analysis: Theory, method and research. SAGE Publications Ltd.

Stam, J., Grootenhuis, M. A., \& Last, B. F. (2001). Social and emotional adjustment in young survivors of childhood cancer. Supportive Care in Cancer, 9, 489-513.

Strom, P., \& Strom, R. (2012). Growing up with social networks and online communities. The Education Digest, 78, 48-51.

Tacon, A. M. (2002). Attachment and cancer: A conceptual integration. Integrative Cancer Therapies, 1(4), 371-381.

Tosone, C., Minami, T., Bettmann, J. E., \& Jasperson, R. A. (2010). New York City social workers after 9/11: Their attachment, resiliency, and compassion fatigue. International Journal of Emergency Mental Health, 12, 103-116.

Tsironi, S., \& Koulierakis, G. (2017). Factors associated with parents' levels of stress in pediatric wards. Journal of Child Health Care, $22,175-185$.

Valcke, M., De Wever, B., Van Keer, H., \& Schellens, T. (2011). Longterm study of safe internet use of young children. Computers \& Education, 57, 1292-1305.

Vannatta, K., Zeller, M., Noll, R. B., \& Koontz, K. (1998). Social functioning of children surviving bone marrow transplantation. Journal of Pediatric Psychology, 3, 169-178.

Vottero, B., \& Rittenmeyer, L. (2012). The hospitalised patients' experience of being in protective/source isolation: A systematic review of qualitative evidence. JBI Library of Systematic Reviews, 10(16), 935-976.

Wentzel, K. R. (2017). Peer relationships, motivation, and academic performance at school. In A. J. Elliot, C. S. Dweck, \& D. S. Yeager (Eds.), Handbook of competence and motivation: Theory and application (pp. 586-603). The Guilford Press.

Wentzel, K. R., Jablansky, S., \& Scalise, N. R. (2020). Peer social acceptance and academic achievement: A meta-analytic study. 
Journal of Educational Psychology. https://doi.org/10.1037/ edu0000468

Willard, V. W. (2018). Social skills interventions for survivors of pediatric brain tumors: A review and reformulation. Pediatric Blood Cancer, 65(12), e27434.

Willard, V. W., Russell, K. M., Long, A., \& Phipps, S. (2019). The impact of connectedness on social functioning in youth with brain tumors. Pediatric Blood \& Cancer, 66, e27607.

World Health Organization. (2014). Recognizing adolescence. World Health Organization. https://apps.who.int/adolescent/seconddecade/section2/page1/recognizing-adolescence.html
Zapf, M. K. (2009). Social work and the environment: Understanding people and place. Canadian Scholars Press Inc.

Publisher's Note Springer Nature remains neutral with regard to jurisdictional claims in published maps and institutional affiliations. 